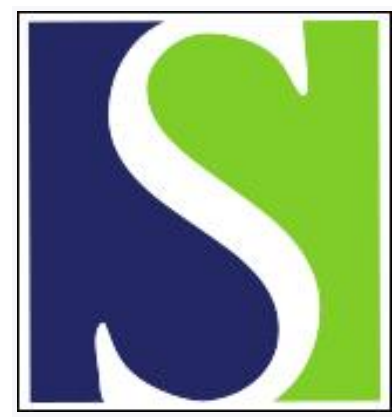

Scand J Work Environ Health 2013;39(6):578-588

https://doi.org/10.5271/sjweh.3380

Published online: 26 Aug 2013, Issue date: 01 Nov 2013

Work-related risk factors for incidence of lateral epicondylitis in a large working population

by Herquelot E, Guéguen A, Roquelaure $Y$, Bodin J, Sérazin C, Ha C, Leclerc A, Goldberg M, Zins M, Descatha A

In this paper, we estimate the incidence of lateral epicondylitis in a large population of workers. We demonstrate the association between high physical exertion combined elbow movements and incidence of lateral epicondylitis. Finally, we highlight the importance of repeated measures of occupational exposures to assess incidence of lateral epicondylitis.

Affiliation: Inserm U1018, UVSQ, Unité de pathologie professionnelle U1018, CHU Poincaré, 104 bd Poincaré, 92380 Garches, France. alexis.descatha@rpc.aphp.fr

The following article refers to this text: 2018;44(6):601-612

Key terms: cohort; elbow pain; epicondylitis; epidemiologic study; incidence; lateral epicondylitis; musculoskeletal disorder; occupation; risk; risk factor; tendinitis; work-related risk factor; working population

This article in PubMed: www.ncbi.nlm.nih.gov/pubmed/23979496 


\title{
Work-related risk factors for incidence of lateral epicondylitis in a large working population
}

\author{
by Eleonore Herquelot, MSc, ${ }^{1,2}$ Alice Guéguen, PhD, ${ }^{1,2}$ Yves Roquelaure, MD, ${ }^{3}$ Julie Bodin, MSc, ${ }^{3}$ Celine \\ Sérazin, MSc, ${ }^{3}$ Catherine Ha, MD, ${ }^{4}$ Annette Leclerc, PhD, ${ }^{1,2}$ Marcel Goldberg, MD, ${ }^{1,2}$ Marie Zins, MD, ${ }^{1,2}$ \\ Alexis Descatha, MD ${ }^{1,2,5}$
}

\begin{abstract}
Herquelot E, Guéguen A, Roquelaure Y, Bodin J, Sérazin C, Ha C, Leclerc A, Goldberg M, Zins M, Descatha A. Work-related risk factors for incidence of lateral epicondylitis in a large working population. Scand J Work Environ Health. 2013;39(6):578-588. doi:10.5271/sjweh.3380
\end{abstract}

\begin{abstract}
Objectives This study aims to estimate the association between repeated measures of occupational risk factors and the incidence of lateral epicondylitis in a large working population.

Methods A total of 3710 workers in a French region were included in 2002-2005, and among them 1046 had a complete follow-up in 2007-2010. At both stages, occupational health physicians assessed the presence of lateral epicondylitis and workers self-reported their occupational exposures. Poisson models were performed to assess the incidence rate ratios (IRR) separately by sex using multiple imputed data.
\end{abstract}

Results The annual incidence rate of lateral epicondylitis was estimated as $1.0[95 \%$ confidence interval $(95 \%$ CI) $0.7-1.3]$ per 100 workers among men and $0.9(95 \%$ CI $0.6-1.3)$ among women. Workers aged $>45$ years had higher incidence than those aged $<30$ years (significant at $10 \%$ ). Among men, high physical exertion combined with elbow flexion/extension or extreme wrist bending ( $>2$ hours/day) was a risk factor, with an age-adjusted IRR of 3.2 (95\% CI 1.5-6.4) for workers exposed at both questionnaires [3.3 (95\% CI 1.4-7.6) among women].

Conclusions This study highlights the importance of temporal dimensions for occupational risk factors on the incidence of lateral epicondylitis. Further research should evaluate the risk associated with the duration and repetition of occupational exposure on the incidence of lateral epicondylitis.

Key terms cohort; elbow pain; epidemiologic study; musculoskeletal disorder; occupation; tendinitis.

Lateral epicondylitis, induced by overuse of extensor muscles leading to inflammation or irritation of the tendon insertion (1), is an important arm disorder with an estimated prevalence of $0.7-4.0 \%$ in the general population (2).

The incidence of lateral epicondylitis has been estimated in general practice $(3,4)$, on the basis of compensation claims (5), hospitals (6), and certain specific activity sectors (7-9). The estimated incidence of lateral epicondylitis ranges from $0.3-1.1$ per 100 patient-years in general practice to $2.0-11.3$ per 100 worker-years in specific activity sectors.
The associations between occupational physical factors and prevalence of lateral epicondylitis have been clearly established, as many studies have demonstrated associations with physically forceful occupational activities (10-18), especially high force combined with high repetition $(15,16)$, awkward posture $(17,18)$ and high physical exertion combined with specific elbow movements (10). Several psychological (depression) and psychosocial (job strain, social support) work factors have also been reported to influence lateral epicondylitis $(7,14,17)$. In a previous report, we studied the association between work factors and the prevalence of

1 Inserm, Centre for research in Epidemiology and Population Health (CESP), U1018, Population-Based Epidemiological Cohorts Research Platform, Villejuif, France.

2 Univ Versailles St-Quentin, Versailles, France.

3 LUNAM Université, Université d'Angers, Laboratoire d'ergonomie et d'épidémiologie en santé au travail (LEEST), Angers, France.

4 Institut de veille sanitaire (InVS), Département santé travail, Saint-Maurice, France.

5 AP-HP, Poincaré University Hospital, Occupational Health Unit, Garches, France.

Correspondence to: Dr Alexis Descatha, Inserm U1018, UVSQ, Unité de pathologie professionnelle U1018, CHU Poincaré, 104 bd Poincaré, 92380 Garches, France. [E-mail: alexis.descatha@rpc.aphp.fr] 
lateral epicondylitis in the same study population (10). The literature review by Van Rijn et al (13) in 2009 revealed that almost all studies on lateral epicondylitis were cross-sectional. The authors found only one cohort study, and concluded that longitudinal studies are needed to confirm the quantitative findings derived from crosssectional studies $(7,8)$.

The worker's history of exposure is an important feature to evaluate the incidence of epicondylitis or musculoskeletal disorders in general, as exposure generally varies over time and the effect of exposure may depend on its duration and the time at which it is measured. No results on repeated exposure are available from the literature for lateral epicondylitis because the few published studies reporting incidence rates provided only one baseline measurement of exposure (7-9).

This study was designed to assess the incidence of lateral epicondylitis in a large population of workers and the effect of repeated measures of occupational risk factors on the associations with the outcome. After investigating the impact of baseline occupational risk factors by means of classical methods, we provide data concerning the effect of duration of exposure and the short- and long-term effects of these exposures by means of more sophisticated and appropriate methods.

\section{Methods}

\section{Study population}

This prospective study was based on two successive surveys of a large sample of workers in the Loire Valley district of Central West France (19). The economic structure of the region, which represents $5.6 \%$ of the French working population, is diversified and similar to that of France (20).

In France, at the time of the first survey, qualified occupational physicians (OP) in charge of the medical surveillance of a group of companies conducted mandatory annual health exams of all salaried workers, including temporary and part-time workers. A total of 83 OP, representative of the region's OP, participated in the study. Subjects were randomly selected from workers undergoing the regularly scheduled mandatory annual health examination between April 2002-2005. All OP were trained to perform a standardized physical examination (20). Subjects completed self-administered questionnaires at the time of this physical examination.

Between 2007-2010, OP performed medical followup of the workers initially included (21), and $43.4 \%$ of the participants attended a follow-up physical examination (figure 1). Some participants were lost to followup between 2007-2010 for organizational reasons (for instance because no appointment was made during this period, there was a change of OP, or the OP followed only active workers). Most retirees, persons on parental or long-term sick leave, and unemployed persons did not undergo a physical examination.

A follow-up questionnaire was sent to participants in 2007 (22). In this study, only self-administered questionnaires returned $\geq 3$ months before the second physical examination were considered in order to limit the possibility of assessment of risk factors occurring after the second measures of outcome; $59.4 \%$ of participants completed a follow-up questionnaire $\geq 3$ months before the second physical examination (ie, 2203 participants, figure 1).

Globally, complete data (both questionnaire and physical examination) were available for $28.2 \%$ of participants (ie, 1046 participants).

All participants signed a written informed consent form and the local ethics committee and the French National Data Protection Committee (CNIL, Commission Nationale de l'Informatique et des Libertés) approved the study.

Only workers who did not report elbow pain at the first physical examination between 2002-2005 were considered for this study, which was designed to study the incidence of lateral epicondylitis.

\section{Outcome}

The OP performed standardized physical examinations, which applied the methodology and clinical tests of the Saltsa consensus for lateral epicondylitis: activitydependent pain directly located around the lateral epicondyle for $\geq 4$ days over the last week and local pain on resisted wrist extension on examination (23). The OP performed these examinations to diagnose epicondylitis only for workers who reported elbow pain. Workers with pain around the lateral epicondyle for $\geq 4$ days over a period of one week in the last 12 months or with lateral epicondylitis confirmed at the time of examination were considered to be cases of interest, called "lateral epicondylitis" in the following results.

The outcome defined for this study was the presence or absence of lateral epicondylitis at the second examination among workers not reporting elbow pain at the first examination. Bilateral elbow musculoskeletal disorders in the same subject were counted as a single disorder.

\section{Risk factors}

Self-assessed exposures to occupational risk factors were available as repeated measures, at least for some of the subjects. Most risk factors evaluated were defined and quantified according to the Saltsa consensus (23). Response categories were initially available on a 4-point Likert-type scale, as follows: never or practically never, 


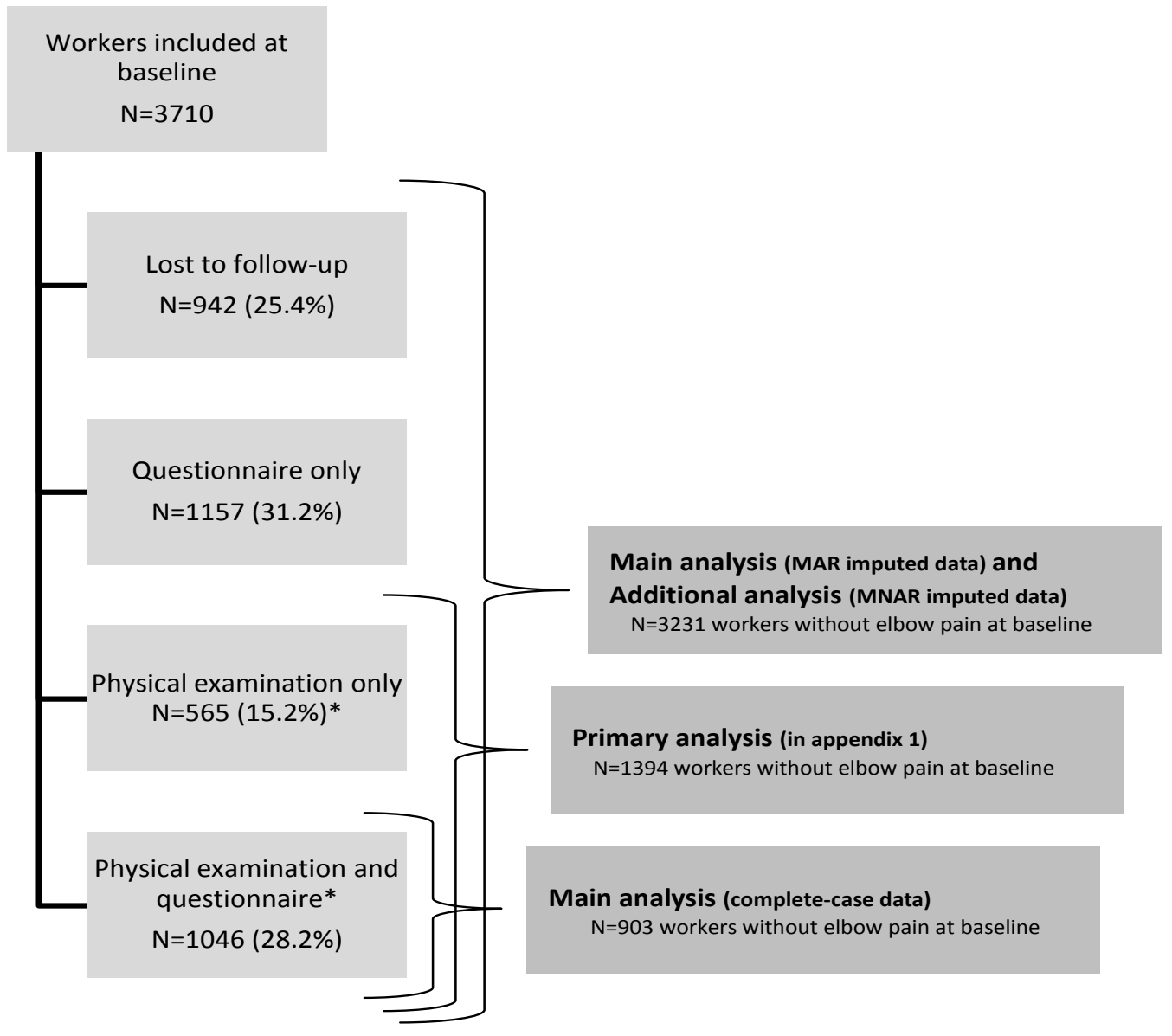

Figure 1. Flow diagram. *Questionnaires with $<3$ months before physical examination were considered as missing,

rarely ( $<2$ hours a day), often $(2-4$ hours a day) and always ( $>4$ hours a day).

This study focused on risk factors previously identified to be associated with the prevalence of epicondylitis in the same population (10). In particular, four risk factors were studied: (i) Age at the time of the first questionnaire was considered in three classes ( $<30$ years, $30-44$ years, $\geq 45$ years); (ii) High repetitiveness was defined by repetitive actions performed $\geq 4$ hours a day; (iii) High physical exertion combined with elbow movements: (a) the Borg rating of perceived exertion scale, ranging from 6-20 and dichotomized into less than hard exertion (6-13) and hard exertion to exhaustion (14-20), was used as a proxy for high physical exertion, (b) elbow flexion and extension, and extreme wrist bending, hereafter called "elbow movements", were dichotomized as $<$ or $>2$ hours a day. The combination of high physical exertion and elbow movements was defined by a two-level variable, which was positive when workers reported high physical exer- tion and $\geq 1$ elbow movement or negative in other cases; (iv) Social support at work was assessed according to the Demand-Control-Support model using the validated French version of the Job Content Questionnaire and was divided into two classes based on the thresholds defined in the national French SUMER (Medical Surveillance of Occupational Risks Exposures) survey (20, 24).

The selection of risk factors studied was based on the results of the baseline cross-sectional analysis (10) and the literature (13). In particular, high physical exertion and elbow movements were specifically considered as a combination because these factors have been identified in previous cross-sectional studies $(10,14,16$, 17) and interactions between similar factors have been previously reported $(10,16,17)$. Associations have also been previously reported with repetitive actions $(12,15$, $16,25)$. Social support was a factor of interest, as the association between this factor and lateral epicondylitis has been previously reported $(10,17)$. 
The data describing exposure were used in two different ways for the two parts of the analysis. In the "primary analysis" (see appendix 1, http://www.sjweh. fi/data_repository.php), only occupational exposures reported at the first questionnaire and their links with follow-up physical examination were considered.

In the main analysis presented in this paper, exposures reported at the first and second questionnaires were used to investigate the long- and short-term effects of exposures. In particular, a composite variable was scored in four classes: (i) never exposed, (ii) exposed in the first phase only (ie, baseline, first questionnaire), (iii) exposed in the second phase only (ie, follow-up, second questionnaire), and (iv) exposed at both the first and second phases.

In addition to self-assessment of elbow pain, the second questionnaire also assessed job changes since 2002 in four categories (no change; new job in the same company; new job in another company; inactive). Workers who were no longer active at the second phase were included in the analysis and considered not to present any occupational exposure at the second phase.

\section{Missing data}

The presence of missing data in this study could depend on risk factors for lateral epicondylitis and the participants' medical history. Multiple imputation analysis with two measures of exposure was performed in order to minimize the potential bias related to complete case analysis when missing follow-up data were not completely missing at random $(26,27)$; all available data were analyzed and the results were applicable to the overall study population. Multiple imputations were performed for missing data on the follow-up for high physical exertion, elbow flexion and extension, extreme wrist bending, high repetitiveness, low social support, elbow pain and lateral epicondylitis at second physical examination and the interval between the first and second physical examinations. Multiple imputations were also performed for missing data on job change and self-assessment of elbow pain as these data were used as auxiliary variables in the imputations.

\section{Missing-at-random hypothesis (MAR imputations)}

We assumed that the mechanism of missing data was dependent on available variables. The imputation models included all relevant predictors, including the previously described risk factors (details in Appendix 2, http://www.sjweh.fi/data_repository.php).

\section{Missing-not-at-random hypothesis (MNAR imputations)}

Sensitivity analyses were performed on the mechanism of missing data: we assumed that missing values for lateral epicondylitis were dependent on measured and unmea- sured variables. In particular, it is reasonable to think that missing data depend on health and employment status and working conditions at the time of the second examination. Firstly, we hypothesized that missing data depend on the specific cause of absence at the second physical examination, a proxy for working conditions or health status. Secondly, we hypothesized that missing data depend on the specific cause of absence and age, a proxy for chosen or imposed employment status (details in Appendix 2).

For each model, imputation models were stratified for gender; 100 datasets were generated (28) (all details concerning the models are presented in Appendix 2). All statistical analyses were performed for each of the 100 datasets separately and recombined using Rubin's rules $(27,29)$.

\section{Statistical analysis}

Incidence rates were estimated for one year of followup using MAR-imputed data. The distribution of exposures, measured at baseline and at follow-up, was also described by occupational categories at baseline using MAR-imputed data.

In a next step, we estimated the associations between risk factors and the incidence of lateral epicondylitis using univariate and multivariate Poisson regressions taking into account the time between physical examinations as the time of event. The results are expressed in terms of incidence rate ratio (IRR) as lateral epicondylitis was assumed to have occurred at the time of the second physical examination, and no lateral epicondylitis was assumed to have occurred and recovered between the two physical examinations. The IRR can be interpreted as the ratio between annual incidence rate in the category considered and the reference category.

The primary analyses consisted of evaluating the association between risk factors at baseline and the incidence of lateral epicondylitis for complete-case workers (ie, workers who attended the second physical examination). The univariate association with age, repetitiveness, combined physical work exposure and low social support from the first questionnaire were considered, and a multivariate model adjusted for age, combined physical work exposure, and repetitiveness on the first questionnaire was also constructed.

The main analyses consisted of evaluation of the association between risk factors measured at baseline and follow-up and the incidence of lateral epicondylitis using MAR-imputed data (ie, on all workers). The multivariate analyses performed resulted in three models: (i) Model 1: adjusted for age and repetitiveness; (ii) Model 2: adjusted for age and combined physical work exposure including physical exertion and elbow movements; (iii) Model 3: adjusted for age, combined physical work exposure, and repetitiveness. 
In view of the relatively high percentage of missing data, the main analyses included also for comparison analyses performed on the complete-case workers (ie, workers followed by OP and who completed the two questionnaires). These analyses (referred to as "additional analysis" below) were completed by the same analyses performed on all workers with specific MNAR imputed data to evaluate the robustness of the results.

All analyses were performed separately for men and women, taking into account sex-related differences in occupations and levels of exposure $(30,31)$. Data analyses for this paper were generated using Stata 10 software for multiple imputations (StataCorp LP, College Station, TX, USA.) and SAS 9.3 software for data analysis and sensitivity analysis (SAS Institute Inc, Cary, NC, USA). Statistical significance was defined as $\mathrm{P}<0.05$.

\section{Results}

\section{Incidence rates}

On imputed data, an estimated 171 workers [103 (5.5\%) men and $68(5.0 \%)$ women] of the 3231 workers who did not report elbow pain at baseline were diagnosed with lateral epicondylitis at the second physical examination. Mean follow-up after the first examination was 5.6 and 5.5 years for men and women, respectively (range: $2-9$ years). The estimated annual incidence rate of lateral epicondylitis was 1.0 [95\% confidence interval $(95 \% \mathrm{CI}) 0.7-1.3]$ per 100 workers for men and 0.9 (95\% CI 0.6-1.3) per 100 workers for women.

\section{Exposure distribution by baseline occupational category}

Unskilled and skilled blue-collar workers, cleaning operatives, and healthcare assistants were highly exposed to high physical exertion combined with elbow movements. At the time of both questionnaires, $26 \%$ of unskilled workers, $21 \%$ skilled workers, and $17 \%$ cleaning operatives and healthcare assistants were exposed among men, while $26 \%, 29 \%$ and $23 \%$ of women were exposed, respectively. At the time of both questionnaires, $5 \%$ of supervisors, $3 \%$ employees, and $1 \%$ executives and civil servants were exposed among men (5\%, $6 \%$, and $2 \%$ for women, respectively). Similar distributions were observed for repetitive tasks with less pronounced differences between occupations.

\section{Primary analysis}

Univariate results for occupational exposures only at baseline indicated that the incidence of epicondyli- tis increased when workers declared highly repetitive tasks, not significantly among men [IRR $1.7(95 \% \mathrm{CI}$ $0.9-3.3)$ ], but significantly among women [IRR 2.3 (95\% CI 1.1-4.9)]. Exposure to high physical exertion combined with elbow movements at the first questionnaire was also a significant risk factor among women with an IRR of $2.3(95 \%$ CI 1.1-5.0) (detailed results in Appendix 1, table A1-1).

\section{Main analyses (MAR-imputed data and complete cases)}

The results of the main analysis using complete-case workers were similar to those of the main analysis using MAR-imputed data mostly with larger confidence intervals (tables A2-1-4, details in Appendix 2). Only the results based on MAR-imputed data are discussed in this section.

Univariate analysis showed that the incidence of epicondylitis increased with age (although not significantly), reaching an IRR of 1.8 (95\% CI $0.7-4.5)$ for men aged $\geq 45$ years compared to men $<30$ years $[6.4$ (95\% CI 0.7-56.2) for women, tables 1-2].

Physical work-related factors were strongly associated with the incidence of epicondylitis. High physical exertion combined with elbow movements was a risk factor with an IRR of 2.9 (95\% CI 1.4-5.9) for workers exposed at both questionnaires versus never exposed among men [3.2 (95\% CI 1.4-7.5) among women]. Male workers exposed to repetitive tasks had a significantly higher incidence of lateral epicondylitis in the univariate analysis. Low social support was not related to the incidence of epicondylitis in the univariate analysis.

In multivariate analyses, the association with high physical exertion combined with at least one elbow movement at both questionnaires remained significant (tables 3-4). Exposure to repetitive tasks at both questionnaires was not significantly associated with the incidence of epicondylitis in multivariate analyses adjusted for high physical exertion combined with elbow movements and age (tables 3-4, model 3). Having been exposed at both questionnaires was more strongly associated with incidence than having been exposed only at the second questionnaire for "elbow-specific combined physical exposure" among men with age-adjusted IRR of 3.2 (95\% CI 1.6-6.4) and 2.7 (95\% CI 1.2-6.1), respectively (although these two IRR were not significantly different). When it could be estimated ( $\geq 1$ case), the association with exposure was significant for "exposed at second questionnaire only" versus "never exposed" and non-significant for "exposed at first questionnaire only" versus "never exposed".

\section{Additional analyses (MNAR-imputed data)}

Sensitivity analysis performed on the main analyses using MNAR-imputed data showed robust results for 
Table 1. Univariate analyses for lateral epicondylitis among men. [IRR=incidence rate ratio; $95 \% \mathrm{Cl}=95 \%$ confidence interval]

\begin{tabular}{|c|c|c|c|c|c|c|c|c|c|c|}
\hline & \multicolumn{5}{|c|}{ Complete case $(\mathrm{N}=491)^{\text {a }}$} & \multicolumn{5}{|c|}{ Multiple imputation ( $\mathrm{N}=1881$ ) } \\
\hline & N & $\mathrm{N}$ (event) & $\mathrm{IRR}$ & $95 \% \mathrm{Cl}$ & P-value & N & $\mathrm{N}$ (event) & IRR & $95 \% \mathrm{Cl}$ & P-value \\
\hline \multicolumn{11}{|l|}{$\begin{array}{l}\text { Personal factors } \\
\text { Age (vears) }\end{array}$} \\
\hline$<30$ & 81 & 5 & 1.0 & .. & & 452 & 18 & 1.0 & .. & \\
\hline $30-44$ & 267 & 14 & 0.9 & $0.3-2.5$ & 0.79 & 857 & 43 & 1.3 & $0.5-3.3$ & 0.52 \\
\hline$\geq 45$ & 143 & 8 & 1.0 & $0.3-3.0$ & 0.95 & 572 & 40 & 1.8 & $0.7-4.5$ & 0.19 \\
\hline \multicolumn{11}{|c|}{$\begin{array}{l}\text { Physical work-related factors } \\
\text { Doing repetitive tasks (exposure } \\
>4 \text { hours/day) }\end{array}$} \\
\hline Never & 350 & 17 & 1.0 & .. & & 1298 & 59 & 1.0 & .. & \\
\hline At first questionnaire & 45 & 2 & 0.9 & $0.2-4.0$ & 0.89 & 218 & 13 & 1.2 & $0.4-3.6$ & 0.74 \\
\hline At second questionnaire & 54 & 2 & 0.7 & $0.2-3.3$ & 0.69 & 192 & 11 & 1.1 & $0.4-3.4$ & 0.80 \\
\hline At both questionnaires & 42 & 6 & 3.0 & $1.2-7.7$ & 0.02 & 173 & 21 & 2.6 & $1.2-5.7$ & 0.02 \\
\hline \multicolumn{11}{|l|}{$\begin{array}{l}\text { Elbow-specific combined } \\
\text { physical exposure }{ }^{b}\end{array}$} \\
\hline Never & 302 & 14 & 1.0 & .. & & 1088 & 41 & 1.0 & .. & . \\
\hline At first questionnaire & 65 & 0 & $\cdot c$ & .. & & 325 & 14 &.${ }^{c}$ & .. & . \\
\hline At second questionnaire & 54 & 6 & 2.5 & $1.0-6.3$ & 0.05 & 201 & 19 & 2.5 & $1.1-5.8$ & 0.03 \\
\hline At both questionnaires & 70 & 7 & 2.1 & $0.9-5.0$ & 0.09 & 267 & 29 & 2.9 & $1.4-5.9$ & $<0.01$ \\
\hline \multicolumn{11}{|l|}{ Psychosocial exposure } \\
\hline Never & 201 & 9 & 1.0 & .. & & 769 & 37 & 1.0 & .. & \\
\hline At first questionnaire & 78 & 4 & 1.1 & $0.3-3.9$ & 0.82 & 347 & 21 & 1.2 & $0.6-2.6$ & 0.60 \\
\hline At second questionnaire & 110 & 5 & 1.0 & $0.3-3.2$ & 0.96 & 402 & 17 & 0.9 & $0.3-2.3$ & 0.77 \\
\hline At both questionnaires & 102 & 9 & 2.0 & $0.8-5.2$ & 0.15 & 363 & 27 & 1.5 & $0.7-3.4$ & 0.30 \\
\hline
\end{tabular}

a Workers with two questionnaires and two physical examinations.

${ }^{\mathrm{b}}$ High physical exertion with elbow flexion/extension $>2$ hours/day or wrist bending $>2$ hours/day.

${ }^{c}$ Not estimable because no events were available on complete case workers.

Table 2. Univariate analyses for lateral epicondylitis among women. [IRR=incidence rate ratio; $95 \% \mathrm{Cl}=95 \%$ confidence interval]

\begin{tabular}{|c|c|c|c|c|c|c|c|c|c|c|}
\hline & \multicolumn{5}{|c|}{ Complete case $(\mathrm{N}=412)^{\text {a }}$} & \multicolumn{5}{|c|}{ Multiple imputation ( $N=1350)$} \\
\hline & $\mathrm{N}$ & N (event) & IRR & $95 \% \mathrm{Cl}$ & P-value & $\mathrm{N}$ & $\mathrm{N}$ (event) & IRR & $95 \% \mathrm{Cl}$ & P-value \\
\hline \multicolumn{11}{|l|}{ Personal factors } \\
\hline$<30$ & 62 & 1 & 1.0 & .. & & 325 & 4 & 1.0 & .. & \\
\hline $30-44$ & 210 & 12 & 3.4 & $0.4-30.9$ & 0.28 & 592 & 40 & 7.7 & $0.9-63.8$ & 0.06 \\
\hline$\geq 45$ & 140 & 5 & 2.1 & $0.2-21.4$ & 0.53 & 433 & 24 & 6.4 & $0.7-56.2$ & 0.09 \\
\hline \multicolumn{11}{|c|}{$\begin{array}{l}\text { Physical work-related factors } \\
\text { Doing repetitive tasks (exposure } \\
>4 \text { hours/day) }\end{array}$} \\
\hline Never & 244 & 8 & 1.0 & .. & . & 792 & 27 & 1.0 & .. & \\
\hline At first questionnaire & 39 & 4 & 3.1 & $0.9-11.1$ & 0.08 & 200 & 18 & 2.5 & $1.0-6.7$ & 0.06 \\
\hline At second questionnaire & 61 & 3 & 1.5 & $0.4-6.0$ & 0.58 & 152 & 6 & 1.1 & $0.3-4.0$ & 0.88 \\
\hline At both questionnaires & 68 & 3 & 1.3 & $0.3-5.4$ & 0.69 & 205 & 16 & 2.3 & $0.8-6.5$ & 0.12 \\
\hline \multicolumn{11}{|l|}{$\begin{array}{l}\text { Elbow-specific combined } \\
\text { physical exposure }{ }^{b}\end{array}$} \\
\hline Never & 262 & 10 & 1.0 & .. & . & 857 & 33 & 1.0 & .. & . \\
\hline At first questionnaire & 45 & 2 & 1.2 & $0.3-5.1$ & 0.83 & 185 & 11 & 1.5 & $0.5-4.7$ & 0.51 \\
\hline At second questionnaire & 50 & 0 &. $\mathrm{c}$ & .. & & 140 & 3 &. $\mathrm{c}$ & .. & . \\
\hline At both questionnaires & 55 & 6 & 2.9 & $1.1-7.8$ & 0.03 & 168 & 21 & 3.2 & $1.4-7.5$ & $<0.01$ \\
\hline \multicolumn{11}{|l|}{ Psychosocial exposure } \\
\hline Low social support & & & & & & & & & & \\
\hline Never & 179 & 5 & 1.0 & .. & . & 583 & 27 & 1.0 & .. & \\
\hline At first questionnaire & 51 & 3 & 2.1 & $0.5-9.4$ & 0.35 & 254 & 13 & 1.1 & $0.3-3.3$ & 0.90 \\
\hline At second questionnaire & 98 & 5 & 1.8 & $0.5-6.7$ & 0.37 & 277 & 14 & 1.0 & $0.4-3.0$ & 0.92 \\
\hline At both questionnaires & 84 & 5 & 2.2 & $0.6-8.1$ & 0.24 & 236 & 14 & 1.3 & $0.5-3.4$ & 0.56 \\
\hline
\end{tabular}

${ }^{a}$ Workers with two questionnaires and two physical examinations.

${ }^{\mathrm{b}}$ High physical exertion with elbow flexion/extension $>2$ hours/day or wrist bending $>2$ hours/day.

${ }^{\mathrm{c}}$ Not estimable because no events were available on complete case workers. 
Table 3. Multivariate analyses for lateral epicondylitis among men. [IRR=incidence rate ratio; $95 \% \mathrm{Cl}=95 \%$ confidence interval]

\begin{tabular}{|c|c|c|c|c|c|c|c|c|c|c|c|c|c|c|c|c|c|c|}
\hline & \multicolumn{9}{|c|}{ Complete case $(\mathrm{N}=491)^{\text {a }}$} & \multicolumn{9}{|c|}{ Multiple imputation ( $\mathrm{N}=1881$ ) } \\
\hline & \multicolumn{3}{|c|}{ Model $1^{b}$} & \multicolumn{3}{|c|}{ Model $2^{b}$} & \multicolumn{3}{|c|}{ Model 3 b } & \multicolumn{3}{|c|}{ Model 1 b } & \multicolumn{3}{|c|}{ Model $2^{b}$} & \multicolumn{3}{|c|}{ Model 3 b } \\
\hline & IRR & $95 \% \mathrm{Cl}$ & $\begin{array}{c}\mathrm{P}- \\
\text { value }\end{array}$ & IRR & $95 \% \mathrm{Cl}$ & $\begin{array}{c}\mathrm{P}- \\
\text { value }\end{array}$ & $\mathrm{IRR}$ & $95 \% \mathrm{Cl}$ & $\begin{array}{c}\mathrm{P}- \\
\text { value }\end{array}$ & IRR & $95 \% \mathrm{Cl}$ & $\begin{array}{c}\mathrm{P}- \\
\text { value }\end{array}$ & IRR & $95 \% \mathrm{Cl}$ & $\begin{array}{c}\mathrm{P}- \\
\text { value }\end{array}$ & IRR & $95 \% \mathrm{Cl}$ & $\begin{array}{c}\text { P- } \\
\text { value }\end{array}$ \\
\hline \multicolumn{19}{|l|}{$\begin{array}{l}\text { Personal factors } \\
\text { Age (years) }\end{array}$} \\
\hline$<30$ & 1 & .. & & 1 & .. & & 1 & .. & & 1 & .. & & 1 & .. & & 1 & 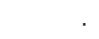 & \\
\hline $30-44$ & 0.9 & $0.3-2.6$ & 0.86 & 0.8 & $0.3-2.1$ & 0.66 & 0.8 & $0.3-2.1$ & 0.69 & 1.4 & $0.5-3.3$ & 0.51 & 1.4 & $0.6-3.5$ & 50.44 & 1.4 & $0.6-3.5$ & 0.44 \\
\hline$\geq 45$ & 1.1 & $0.3-3.4$ & 0.91 & 0.9 & $0.3-2.7$ & 0.87 & 0.9 & $0.3-2.6$ & 0.86 & 2 & $0.8-4.9$ & 0.15 & 2.1 & $0.9-5.2$ & 0.1 & 2.2 & $0.9-5.4$ & 0.09 \\
\hline \multicolumn{19}{|l|}{$\begin{array}{l}\text { Physical work- } \\
\text { related factors }\end{array}$} \\
\hline \multicolumn{19}{|l|}{$\begin{array}{l}\text { Doing re- } \\
\text { petitive tasks } \\
\text { (exposure }>4 \\
\text { hours/day) }\end{array}$} \\
\hline Never & 1 & .. & & & & & 1 & .. & & 1 & .. & & & & & 1 & .. & \\
\hline $\begin{array}{l}\text { At first } \\
\text { questionnaire }\end{array}$ & 0.9 & $0.2-4.2$ & 0.91 & & & & 1.1 & $0.3-4.5$ & 0.87 & 1.2 & $0.4-3.6$ & 0.73 & & & & 1.2 & $0.4-3.6$ & 0.78 \\
\hline $\begin{array}{l}\text { At second } \\
\text { questionnaire }\end{array}$ & 0.7 & $0.2-3.4$ & 0.71 & & & & 0.5 & $0.1-2.1$ & 0.36 & 1.2 & $0.4-3.5$ & 0.76 & & & & 0.8 & $0.3-2.6$ & 0.77 \\
\hline $\begin{array}{l}\text { At both } \\
\text { questionnaires }\end{array}$ & 3 & $1.1-8.0$ & 0.02 & & & & 2.6 & $1.0-6.7$ & 0.05 & 2.8 & $1.2-6.2$ & 0.01 & & & & 1.9 & $0.8-4.6$ & 0.17 \\
\hline \multicolumn{19}{|l|}{$\begin{array}{l}\text { Elbow-specific } \\
\text { combined } \\
\text { physical expo- } \\
\text { sure }^{c}\end{array}$} \\
\hline Never & & & & 1 & .. & . & 1 & .. &. & & & & 1 & .. & & 1 & .. & \\
\hline $\begin{array}{l}\text { At first } \\
\text { questionnaire }\end{array}$ & & & &.$^{d}$ & .. & . &.$^{d}$ & .. & . & & & & ${ }^{d}$ & .. & & ${ }^{d}$ &.. & \\
\hline $\begin{array}{l}\text { At second } \\
\text { questionnaire }\end{array}$ & & & & 2.6 & $1.0-6.5$ & 0.04 & 2.5 & $1.0-6.5$ & 0.05 & & & & 2.7 & $1.1-6.1$ & 0.02 & 2.5 & $1.0-6.0$ & 0.05 \\
\hline $\begin{array}{l}\text { At both } \\
\text { questionnaires }\end{array}$ & & & & 2.1 & $0.9-5.1$ & 0.1 & 1.7 & $0.6-4.2$ & 0.29 & & & & 3.2 & $1.5-6.4$ & $4<0.01$ & 2.7 & $1.2-6.0$ & 0.01 \\
\hline
\end{tabular}

a Workers with two questionnaires and two physical examinations.

${ }^{b}$ Poisson model adjusted on specified variables with time between examination as time to event

c High physical exertion with elbow flexion/extension $>2$ hours/day or wrist bending $>2$ hours/day

d Not estimable because no events were available on complete case workers.

univariate and multivariate models. Details for model 3 concerning the main categories of interest are presented in Appendix 2 (tables A2-3 and A2-4), while other results are not shown.

\section{Discussion}

This study provides an estimate of the incidence of lateral epicondylitis in a large population of workers and highlights the role of physical work-related risk factors for the development of lateral epicondylitis, particularly for high physical exertion combined with elbow and repetitive movements. The different analyses emphasize that repeated self-assessment of high exposure is strongly associated with the incidence of lateral epicondylitis.

The annual incidence rate of lateral epicondylitis was estimated to be 1.0 (95\% CI $0.7-1.3)$ per 100 workers among men and 0.9 (95\% CI 0.7-1.3) per 100 workers among women. Feleus et al (4) reported an annual inci- dence rate of 1.1 per 100 patients in general practice in Holland and Silverstein et al (5) reported an annual incidence rate for claims of 0.1 per 100 full-time workers in the Washington state. In France, Roquelaure et al (7) reported an annual incidence rate of 2.1 per 100 workers in a shoe factory and Leclerc et al (9) reported an annual incidence rate of 4.0 per 100 workers highly exposed to physical constraints. As stated by Palmer et al (32), job title is an important determinant for epicondylitis, which could explain the observed difference with other studies, as the present study population was a general working population with various kinds of activities including low-exposed jobs.

The main result of this study is the strong effect of combined perceived physical exertion with elbow movements on the incidence of epicondylitis. This result is in agreement with previous findings concerning an excess incidence of epicondylitis among manual workers (5, 8 ). In Leclerc et al (7), "turn and screw" wrist and elbow movements were also identified as a risk factor for epicondylitis, similar to the "elbow movements" investigated in the present study. Repetitive movements 
Table 4. Multivariate analyses for lateral epicondylitis among women. [IRR=incidence rate ratio; $95 \% \mathrm{Cl}=95 \%$ confidence interval]

\begin{tabular}{|c|c|c|c|c|c|c|c|c|c|c|c|c|c|c|c|c|c|c|}
\hline & \multicolumn{9}{|c|}{ Complete case $(\mathrm{N}=412)^{\text {a }}$} & \multicolumn{9}{|c|}{ Multiple imputation $(\mathrm{N}=1350)$} \\
\hline & \multicolumn{3}{|c|}{ Model $1^{b}$} & \multicolumn{3}{|c|}{ Model $2^{b}$} & \multicolumn{3}{|c|}{ Model 3 b } & \multicolumn{3}{|c|}{ Model $1^{b}$} & \multicolumn{3}{|c|}{ Model $2^{b}$} & \multicolumn{3}{|c|}{ Model 3 b } \\
\hline & IRR & $95 \% \mathrm{Cl}$ & $\begin{array}{c}\mathrm{P}- \\
\text { value }\end{array}$ & IRR & $95 \% \mathrm{Cl}$ & $\begin{array}{c}\mathrm{P}- \\
\text { value }\end{array}$ & $\mathrm{IRR}$ & $95 \% \mathrm{Cl}$ & $\begin{array}{c}\mathrm{P}- \\
\text { value }\end{array}$ & IRR & $95 \% \mathrm{Cl}$ & $\begin{array}{c}\mathrm{P}- \\
\text { value }\end{array}$ & IRR & $95 \% \mathrm{Cl}$ & $\begin{array}{c}P- \\
\text { value }\end{array}$ & IRR & $95 \% \mathrm{Cl}$ & $\begin{array}{c}\mathrm{P}- \\
\text { value }\end{array}$ \\
\hline \multicolumn{19}{|l|}{$\begin{array}{l}\text { Personal factors } \\
\text { Age (years) }\end{array}$} \\
\hline$<30$ & 1.0 & .. & & 1.0 & .. & & 1.0 & .. & & 1.0 & .. & & 1.0 & .. & & 1.0 &.. & \\
\hline $30-44$ & 3.4 & $0.4-29.8$ & 0.27 & 4.3 & $0.6-31.3$ & 0.15 & 4.3 & $0.6-30.4$ & 0.15 & 8.0 & $1.0-63.4$ & 0.05 & 7.9 & $1.0-61.2$ & 0.05 & 8.3 & $1.0-63.7$ & 0.04 \\
\hline$\geq 45$ & 2.0 & $0.2-19.0$ & 0.57 & 2.5 & $0.3-20.2$ & 0.38 & 2.1 & $0.3-16.4$ & 0.49 & 6.5 & $0.8-54.7$ & 0.09 & 6.3 & $0.8-51.2$ & 0.09 & 6.4 & $0.8-51.9$ & 0.08 \\
\hline \multicolumn{19}{|l|}{$\begin{array}{l}\text { Physical work- } \\
\text { related factors } \\
\text { Doing repetitive } \\
\text { tasks (exposure } \\
>4 \text { hours/day) }\end{array}$} \\
\hline Never & 1.0 & .. & & & & & 1.0 & .. & & 1.0 &.. & 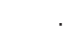 & & & & 1.0 &.. & \\
\hline $\begin{array}{l}\text { At first } \\
\text { questionnaire }\end{array}$ & 3.3 & $0.9-11.8$ & 0.07 & & & & 3.0 & $0.9-9.9$ & 0.08 & 2.7 & $1.0-7.0$ & 0.04 & & & & 2.4 & $0.9-6.4$ & 0.08 \\
\hline $\begin{array}{l}\text { At second } \\
\text { questionnaire }\end{array}$ & 1.6 & $0.4-6.4$ & 0.53 & & & & 1.2 & $0.3-4.6$ & 0.75 & 1.0 & $0.3-3.8$ & 0.94 & & & & 0.9 & $0.2-3.1$ & 0.84 \\
\hline $\begin{array}{l}\text { At both } \\
\text { questionnaires }\end{array}$ & 1.4 & $0.3-5.7$ & 0.65 & & & & 0.9 & $0.2-3.4$ & 0.85 & 2.2 & $0.8-6.3$ & 0.13 & & & & 1.5 & $0.5-4.5$ & 0.51 \\
\hline \multicolumn{19}{|l|}{$\begin{array}{l}\text { Elbow-specific } \\
\text { combined phys- } \\
\text { ical exposure c }\end{array}$} \\
\hline Never & & & & 1.0 & .. & & 1.0 &.. & & & & & 1.0 & .. & . & 1.0 & .. & \\
\hline $\begin{array}{l}\text { At first } \\
\text { questionnaire }\end{array}$ & & & & 1.3 & $0.3-5.6$ & 0.74 & 1.1 & $0.2-4.7$ & 0.92 & & & & 1.5 & $0.5-4.7$ & 0.48 & 1.2 & $0.4-3.9$ & 0.75 \\
\hline $\begin{array}{l}\text { At second } \\
\text { questionnaire }\end{array}$ & & & &.$d$ & .. & &.$d$ & .. & 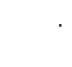 & & & &.$d$ & .. & &.$d$ & .. & \\
\hline $\begin{array}{l}\text { At both } \\
\text { questionnaires }\end{array}$ & & & & 3.4 & $1.3-9.2$ & 0.01 & 3.5 & $1.2-10.3$ & 0.02 & & & & 3.3 & $1.4-7.6$ & $<0.01$ & 2.9 & $1.2-7.4$ & 0.02 \\
\hline
\end{tabular}

a Workers with two questionnaires and two physical examinations.

${ }^{b}$ Poisson model adjusted on specified variables with time between examination as time to event.

c High physical exertion with elbow flexion/extension more than 2 hours/day or wrist bending more than 2 hours/day.

${ }^{\mathrm{d}}$ Not estimable because no events were available on complete case workers.

was also a risk factor in univariate analysis among men, a result similar to the high incidence of epicondylitis reported among workers exposed to repetitive gestures (7) and associations with repetitive actions in cross-sectional studies $(12,15,16,25)$. However, our results suggest that repetition alone might be a proxy for more specific elbow exposure. Interaction found in other cross-sectional studies could not be explored here and cannot be excluded, even though no statistical interaction was found between force and repetition in a previous cross-sectional analysis on the same data (10).

The quality of self-reported biomechanical exposure is always a concern in occupational health $(33,34)$. In this study, we cannot exclude the possible effect of health status on self-reported exposures by workers, particularly for workers with an assessment of exposure close to and possibly before the assessment of the outcome. However, misclassification is expected to be limited by the use of questions comprising a high level of details and the use of a longitudinal design with repeated measures. Furthermore, the job titles corresponding to high physical exposure corresponded to the expected jobs.

An impact of social support on the incidence of epicondylitis was not observed in this study. Previous studies have reported a higher incidence for strenuous jobs in a meat factory (8) and depression was also identified as a risk factor in repetitive work (7).

The primary analyses on the link between exposure measured at baseline and the incidence of lateral epicondylitis is the most usual approach to the analysis of this type of data, limiting the risk factors to the baseline assessment. This analysis showed consistent results with the main analyses based on measures at both baseline and follow-up, but it was based only on a part of the available information. This analysis compared also the subgroup of workers exposed at both questionnaires to the subgroup of workers exposed at the first or second questionnaire and those who were never exposed. The main analyses on both measures also indirectly investigated the effect of duration of exposure on the incidence of lateral epicondylitis, as the number of reports of exposure can be considered to be a rough approximation of duration of exposure (workers only exposed at the second questionnaire were exposed for a shorter period of time than those exposed at both questionnaires). The results reported here are compatible with the hypothesis that the incidence of lateral epicondylitis increases with the duration of exposure. In particular, the "effect" of 
being exposed at the time of the two questionnaires appeared to be greater (although not significantly) than that of being exposed only at the second questionnaire for elbow-specific combined physical exposure among men. The results about exposure measured at only one time also suggest that exposure tends to have a shortterm rather than a delayed effect.

Although the IRR appeared to increase with age, age was not a significant risk factor in this study. Age is a recognized risk factor for prevalence $(10,16,18)$ and incidence of lateral epicondylitis (7). However, the substantial rate of subjects lost to follow-up among older and younger workers resulted in a lack of power to estimate the effect of age. Older workers without elbow pain at baseline also constituted a specific subgroup, as they remained unaffected although the majority of them have experienced the same exposure before and during the study.

The main limitation of this study is the large proportion of missing data, with potential issues related to random variations and lack of precision. A bias may also arise in complete-case analysis when the mechanism responsible for missing data is not completely random. Multiple imputation analysis is designed to reduce this bias when data are missing at random. In this study, complete-case and MAR multiple imputation analyses give similar results. Moreover, the sensitivity analysis on missingness mechanism (MNAR-imputed data) demonstrates the robustness of these results in terms of specific departures from the missing-at-random mechanism related to working conditions and health status during the second phase of the study.

Another concern in this study is the assumption that no event occurred between the two measures in view of the relatively long interval between physical examinations. The incidence rate of lateral epicondylitis could be underestimated as some workers may develop and recover from lateral epicondylitis between the two examinations, and it would therefore not be detected at the second examination. This would also have resulted in a slight underestimation of the IRR of exposure because manual workers are more susceptible to recurrence than nonmanual workers (2). The incidence rate of lateral epicondylitis could also be underestimated since it was assumed that the event occurred at the time of second examination. This assumption has no consequence on IRR in this study.

This study highlights the importance of temporal dimensions for occupational risk factors, in particular repetitive tasks and high physical exertion with elbow movements, on the incidence of lateral epicondylitis. Further research should evaluate the risk associated with the duration and repetition of occupational exposure (including interactions) on the incidence and recurrence of lateral epicondylitis using repeated measures with a relevant time frame.

\section{Acknowledgments}

We are grateful to the occupational physicians involved in the sentinel network: Doctors Abonnat, Banon, Bardet, Becquemie, Bertin, Bertrand, Bidron, Biton, Bizouarne, Boisse, Bonamy, Bonneau, Bouguer-Diquelou, BourrutLacouture, Breton, Caillon, Cesbron, Chisacof, Chotard, Compain, Coquin-Georgeac, Cordes, Couet, Coutand, Danielou, Darcy, Davenas, De Lansalut, De Lescure, Diquelou, Dopsent, Dufrenne-Benetti, Dupas, Evano, Fache, Fontaine, Frampas-Chotard, Guillier, Guillimin, Harinte, Harrigan, Hervio, Hirigoyen, Jahan, Jube, Kalfon, Labraga, Laine-Colin, Laventure, Le Dizet, Lechevalier, Le Clerc, Ledenvic, Leroux, Leroy-Maguer, Levrard, Levy, Logeay, Lucas, Mallet, Martin-Laurent, Mazoyer, Meritet, Michel, Migne-Cousseau, Moisan, Page, Patillot, Pinaud, Pineau, Pizzalla, Plessis, Plouhinec, Raffray, Robin-Riom, Roussel, Russu, Saboureault, Schlindwein, Soulard, Thomson, Treillard and Tripodi.

The French Institute for Public Health Surveillance (Saint-Maurice, France) (grant 9/25/2002-5 "réseau expérimental de surveillance des troubles musculosquelettiques", "étude du pronostic médical et professionnel de certains TMS à partir des données du réseau pays de la Loire") and the French National Research Agency (ANR-Grant SEST-06-36) supported this study.

\section{References}

1. Walz DM, Newman JS, Konin GP, Ross G. Epicondylitis: Pathogenesis, Imaging, and Treatment. Radiographics. 2010;30(1):167-84. http://dx.doi.org/10.1148/rg.301095078.

2. Shiri R, Viikari-Juntura E. Lateral and medial epicondylitis: Role of occupational factors. Best practice \& research. Clinical rheumatology. 2011;25(1):43. http://dx.doi.org/10.1016/j. berh.2011.01.013.

3. Hamilton PG. The prevalence of humeral epicondylitis: a survey in general practice. The Journal of the Royal College of General Practitioners. 1986;36(291):464.

4. Feleus A, Bierma-Zeinstra SMA, Miedema HS, Verhagen AP, Nauta AP, Burdorf A, et al. Prognostic indicators for nonrecovery of non-traumatic complaints at arm, neck and shoulder in general practice - 6 months follow-up. Rheumatology. 2007;46(1):169-76. http://dx.doi.org/10.1093/rheumatology/ kel164.

5. Silverstein B, Viikari-Juntura E, Kalat J. Use of a prevention index to identify industries at high risk for work-related musculoskeletal disorders of the neck, back, and upper extremity in Washington state, 1990-1998. Am J Ind Med. 2002;41(3):149-69. http://dx.doi.org/10.1002/ajim.10054.

6. Verhaar JA. Tennis elbow. Anatomical, epidemiological and therapeutic aspects. Int Orthop. 1994;18(5):263-7. 
7. Leclerc A, Landre MF, Chastang JF, Niedhammer I, Roquelaure Y. Upper-limb disorders in repetitive work. Scand J Work Environ Health. 2001;27(4):268-78. http://dx.doi. org/10.5271/sjweh.614.

8. Kurppa K, Viikari-Juntura E, Kuosma E, Huuskonen M, Kivi P. Incidence of tenosynovitis or peritendinitis and epicondylitis in a meat-processing factory. Scand J Work Environ Health. 1991;17(1):32-7. http://dx.doi.org/10.5271/sjweh.1737.

9. Roquelaure Y, Mariel J, Fanello S, Boissière J-C, Chiron $\mathrm{H}$, Dano C, et al. Active epidemiological surveillance of musculoskeletal disorders in a shoe factory. Occup Environ Med. 2002;59(7):452-8. http://dx.doi.org/10.1136/oem.59.7.452.

10. Herquelot E, Bodin J, Roquelaure Y, Ha C, Leclerc A, Goldberg $\mathrm{M}$, et al. Work-related risk factors for lateral epicondylitis and other cause of elbow pain in the working population. Am J Ind Med. 2013 Apr;56(4):4009. http://dx.doi.org/10.1002/ ajim. 22140 .

11. Ritz BR. Humeral epicondylitis among gas- and waterworks employees. Scand J Work Environ Health. 1995;21(6):478-86. http://dx.doi.org/10.5271/sjweh.64.

12. Ono Y, Nakamura R, Shimaoka M, Hiruta S, Hattori Y, Ichihara $\mathrm{G}$, et al. Epicondylitis among cooks in nursery schools. Occup Environ Med. 1998;55(3):172-9. http://dx.doi.org/10.1136/ oem.55.3.172.

13. Van Rijn RM, Huisstede BMA, Koes BW, Burdorf A. Associations between work-related factors and specific disorders at the elbow: a systematic literature review. Rheumatology (Oxford). 2009;48(5):528-36. http://dx.doi. org/10.1093/rheumatology/kep013.

14. Walker-Bone K, Palmer KT, Reading I, Coggon D, Cooper C. Occupation and epicondylitis: a population-based study. Rheumatology (Oxford). 2012;51(2):305-10. http://dx.doi. org/10.1093/rheumatology/ker228.

15. Chiang HC, Ko YC, Chen SS, Yu HS, Wu TN, Chang PY. Prevalence of shoulder and upper-limb disorders among workers in the fish-processing industry. Scand J Work Environ Health. 1993;19(2):126-31. http://dx.doi.org/10.5271/ sjweh. 1496.

16. Shiri R, Viikari-Juntura E, Varonen H, Heliövaara M. Prevalence and determinants of lateral and medial epicondylitis: a population study. Am J Epidemiol. 2006;164(11):1065-74. http://dx.doi.org/10.1093/aje/kwj325.

17. Haahr JP, Andersen JH. Physical and psychosocial risk factors for lateral epicondylitis: a population based case-referent study. Occup Environ Med. 2003;60(5):322-9. http://dx.doi. org/10.1136/oem.60.5.322.

18. Fan ZJ, Silverstein BA, Bao S, Bonauto DK, Howard NL, Spielholz PO, et al. Quantitative exposure-response relations between physical workload and prevalence of lateral epicondylitis in a working population. Am J Ind Med. 2009;52(6):479-90. http://dx.doi.org/10.1002/ajim.20700.

19. Ha C, Roquelaure Y, Leclerc A, Touranchet A, Goldberg $\mathrm{M}$, Imbernon E. The French Musculoskeletal Disorders Surveillance Program: Pays de la Loire network. Occup Environ Med. 2009;66(7):471-9. http://dx.doi.org/10.1136/ oem.2008.042812.
20. Roquelaure Y, Ha C, Leclerc A, Touranchet A, Sauteron $\mathrm{M}$, Melchior $\mathrm{M}$, et al. Epidemiologic surveillance of upper-extremity musculoskeletal disorders in the working population. Arthritis Rheum. 2006;55(5):765-78. http:// dx.doi.org/10.1002/art.22222.

21. Bodin J, Ha C, Petit Le Manac'h A, Sérazin C, Descatha A, Leclerc A, et al. Risk factors for incidence of rotator cuff syndrome in a large working population. Scand J Work Environ Health. 2012;38(5):436-46. http://dx.doi. org/10.5271/sjweh.3285.

22. Bodin J, Ha C, Sérazin C, Descatha A, Leclerc A, Goldberg $\mathrm{M}$, et al. Effects of Individual and Work-related Factors on Incidence of Shoulder Pain in a Large Working Population. J Occup Health. 2012;54(4):278-88. http://dx.doi.org/10.1539/ joh.11-0262-OA.

23. Sluiter JK, Rest KM, Frings-Dresen MH. Criteria document for evaluating the work-relatedness of upper-extremity musculoskeletal disorders. Scand J Work Environ Health. 2001;27 Suppl 1:1-102. http://dx.doi.org/10.5271/sjweh.637.

24. Niedhammer I, Chastang JF, Gendrey L, David S, Degioanni S. Propriétés psychométriques de la version française des échelles de la demande psychologique, de la latitude décisionnelle et du soutien social du "Job Content Questionnaire" de Karasek: résultats de l'enquête nationale SUMER [Psychometric properties of the French version of Karasek's "Job Content Questionnaire" and its scales measuring psychological pressures, decisional latitude and social support: the results of the SUMER]. Sante Publique. 2006;18(3):413-27. http:// dx.doi.org/10.3917/spub.063.0413.

25. Hansson GA, Balogh I, Ohlsson K, Pålsson B, Rylander L, Skerfving S. Impact of physical exposure on neck and upper limb disorders in female workers. Appl Ergon. 2000;31(3):301-10. http://dx.doi.org/10.1016/S00036870(99)00047-2.

26. White IR, Royston P, Wood AM. Multiple imputation using chained equations: Issues and guidance for practice. Statistics in medicine. 2011;30(4):377-99. http://dx.doi.org/10.1002/ sim.4067.

27. Schafer JL, Graham JW. Missing data: our view of the state of the art. Psychological methods. 2002;7(2):147. http://dx.doi. org/10.1037/1082-989X.7.2.147.

28. Royston P. Multiple imputation of missing values: update of ice. Stata Journal. 2005;5(4):527.

29. Little RJA, Rubin DB. Statistical analysis with missing data. Wiley New York; 1987.

30. Messing K, Stock SR, Tissot F. Should studies of risk factors for musculoskeletal disorders be stratified by gender? Lessons from the 1998 Québec Health and Social Survey. Scand J Work Environ Health. 2009;35(2):96-112. http://dx.doi. org/10.5271/sjweh.1310.

31. Silverstein B, Fan ZJ, Smith CK, Bao S, Howard N, Spielholz P, et al. Gender adjustment or stratification in discerning upper extremity musculoskeletal disorder risk? Scand J Work Environ Health. 2009;35(2):113-26. http://dx.doi.org/10.5271/sjweh.1309.

32. Palmer KT, Harris EC, Coggon D. Compensating occupationally 
related tenosynovitis and epicondylitis: a literature review. Occup Med (Lond). 2007;57(1):67-74. http://dx.doi. org/10.1093/occmed/kq1127.

33. Leclerc A. Exposure assessment in ergonomic epidemiology: is there something specific to the assessment of biomechanical exposures? Occup Environ Med. 2005;62(3):143-4. http:// dx.doi.org/10.1136/oem.2004.017889.

34. Barrero LH, Katz JN, Dennerlein JT. Validity of self-reported mechanical demands for occupational epidemiologic research of musculoskeletal disorders. Scand J Work Environ Health. 2009;35(4):245-60. http://dx.doi.org/10.5271/sjweh.1335.

35. Ismail K, Thomas SM, Maissi E, Chalder T, Schmidt U, Bartlett J, et al. Motivational enhancement therapy with and without cognitive behavior therapy to treat type 1 diabetes. Ann Intern Med. 2008;149:708-19. http://dx.doi. org/10.7326/0003-4819-149-10-200811180-00005.

Received for publication: 29 January 2013 